\title{
Histamine stimulates the proliferation of small and large cholangiocytes by activation of both $\mathrm{IP}_{3} / \mathrm{Ca}^{2+}$ and CAMP-dependent signaling mechanisms
}

Heather L Francis ${ }^{1,2,3}$, Sharon DeMorrow ${ }^{1,2}$, Antonio Franchitto ${ }^{4,5}$, Julie K Venter ${ }^{2}$, Romina A Mancinelli ${ }^{4}$, Mellanie A White ${ }^{2}$, Fanyin Meng ${ }^{2,3}$, Yoshiyuki Ueno ${ }^{6}$, Guido Carpino ${ }^{7}$, Anastasia Renzi ${ }^{1,4}$, Kimberly K Baker ${ }^{3}$, Hannah E Shine ${ }^{3}$, Taylor C Francis ${ }^{3}$, Eugenio Gaudio ${ }^{4}$, Gianfranco D Alpini ${ }^{1,2,8,10}$ and Paolo Onori ${ }^{9,10}$

Although large cholangiocytes exert their functions by activation of cyclic adenosine $3^{\prime}, 5^{\prime}$-monophosphate (cAMP), $\mathrm{Ca}^{2+}$-dependent signaling regulates the function of small cholangiocytes. Histamine interacts with four receptors, $\mathrm{H} 1-\mathrm{H} 4 \mathrm{HRs}$. $\mathrm{H} 1 \mathrm{HR}$ acts by $\mathrm{G} \alpha \mathrm{q}$ activating $\mathrm{IP}_{3} / \mathrm{Ca}^{2+}$, whereas $\mathrm{H} 2 \mathrm{HR}$ activates $\mathrm{G} \alpha_{\mathrm{s}}$ stimulating cAMP. We hypothesize that histamine increases biliary growth by activating $\mathrm{H} 1 \mathrm{HR}$ on small and $\mathrm{H} 2 \mathrm{HR}$ on large cholangiocytes. The expression of $\mathrm{H} 1-\mathrm{H} 4 \mathrm{HRs}$ was evaluated in liver sections, isolated and cultured (normal rat intrahepatic cholangiocyte culture (NRIC)) cholangiocytes. In vivo, normal rats were treated with histamine or $\mathrm{H} 1-\mathrm{H} 4 \mathrm{HR}$ agonists for 1 week. We evaluated: (1) intrahepatic bile duct mass (IBDM); (2) the effects of histamine, H1HR or H2HR agonists on NRIC proliferation, $\mathrm{IP}_{3}$ and cAMP levels and PKC $\alpha$ and protein kinase A (PKA) phosphorylation; and (3) PKC $\alpha$ silencing on H1HR-stimulated NRIC proliferation. Small and large cholangiocytes express H1-H4HRs. Histamine and the H1HR agonist increased small IBDM, whereas histamine and the H2HR agonist increased large IBDM. H1HR agonists stimulated $\mathrm{IP}_{3}$ levels, as well as PKC $\alpha$ phosphorylation and NRIC proliferation, whereas H2HR agonists increased cAMP levels, as well as PKA phosphorylation and NRIC proliferation. The H1HR agonist did not increase proliferation in PKC $\alpha$ siRNA-transfected NRICs. The activation of differential signaling mechanisms targeting small and large cholangiocytes is important for repopulation of the biliary epithelium during pathologies affecting different-sized bile ducts.

Laboratory Investigation (2012) 92, 282-294; doi:10.1038/labinvest.2011.158; published online 7 November 2011

KEYWORDS: biliary epithelium; biogenic amines; cAMP; heterogeneity; $\mathrm{IP}_{3}$; secretin receptor

Cholangiocytes, which line intrahepatic and extrahepatic bile ducts, ${ }^{1,2}$ modify canalicular bile while it is being delivered from the bile canaliculus to the small intestine. ${ }^{3,4}$ Secretin stimulates secretion of ductal bile by interaction with secretin receptors $(\mathrm{SRs})^{1,3}$ that increases the synthesis of cyclic adenosine $3^{\prime}, 5^{\prime}$-monophosphate (cAMP), phosphorylation of protein kinase A (PKA), opening of cystic fibrosis transmembrane conductance regulator with subsequent activation of the $\mathrm{Cl}^{-} / \mathrm{HCO}_{3}^{-}$anion exchanger 2 (AE2), leading to enhanced bicarbonate secretion into bile. ${ }^{1,3,5-7}$

Cholangiocytes, which are constitutively mitotically dormant, ${ }^{8,9}$ markedly proliferate or are damaged in human cholangiopathies ${ }^{10}$ and in animal models of cholestasis, including bile duct ligation (BDL) and acute carbon tetrachloride $\left(\mathrm{CCl}_{4}\right)$ administration. ${ }^{11}$ As cholangiocytes are the only cells expressing SR in the rodent liver, ${ }^{12}$ changes in

${ }^{1}$ Department of Internal Medicine, Scott and White Digestive Disease Research Center, Scott and White Hospital and Texas A\&M Health Science Center, College of Medicine, Temple, TX, USA; ${ }^{2}$ Division of Gastroenterology, Department of Medicine, Scott and White Hospital and Texas A\&M Health Science Center, College of Medicine, Temple, TX, USA; ${ }^{3}$ Division of Research and Education, Scott and White Hospital and Texas A\&M Health Science Center, College of Medicine, Temple, TX, USA; ${ }^{4}$ Department of Anatomical, Histological, Forensic Internal Medicine and Orthopedics Sciences, 'La Sapienza', Rome, Italy; ${ }^{5}$ Eleonora Lonillard Spencer Cenci Foundation, Rome, Italy; ${ }^{6}$ Division of Gastroenterology, Tohoku University Graduate School of Medicine, Sendai, Japan; ${ }^{7}$ Department Health Science, University of Rome'Foro Italico', Italy; ${ }^{8}$ Division Research, Central Texas Veterans Health Care System, Scott and White Hospital and Texas A\&M Health Science Center, College of Medicine, Temple, TX, USA and ${ }^{9}$ Department of Experimental Medicine, State University of L'Aquila, L'Aquila, Italy

Correspondence: Dr GD Alpini, PhD, Scott and White Digestive Diseases Research Center, Dr Nicholas C Hightower Centennial Chair of Gastroenterology, Central Texas Veterans Health Care System, Texas A\&M Health Science Center College of Medicine, Olin E. Teague Medical Center, 1901 South First Street, Building 205, 1R60, Temple, TX 76504, USA or Associate Professor P Onori, MD, Department of Experimental Medicine, University of L'Aquila, Via Vetoio, Coppito 2, 67100 L'Aquila, Italy. E-mails: galpini@tamu.edu or galpini@medicine.tamu.edu or paolo.onori@univaq.it

${ }^{10} \mathrm{Dr}$ Onori and Alpini share the last authorship. 
the expression of this receptor are key for functionally evaluating the degree of biliary growth/loss. ${ }^{3,8,9,11,13,14}$ For example, treatment of normal rats with forskolin induces cholangiocyte hyperplasia and increases secretin-stimulated choleresis ${ }^{13}$ that is similar to that seen in the BDL model. ${ }^{3}$ In models of biliary damage (eg, after acute $\mathrm{CCl}_{4}$ administration), there is loss of secretin-stimulated ductal secretion. ${ }^{11}$ Models of biliary proliferation/loss are critically important to better understand the development of cholangiopathies, including primary biliary cirrhosis and primary sclerosing cholangitis. Two main signaling pathways are important for regulating cholangiocyte proliferation: the $\mathrm{IP}_{3} / \mathrm{Ca}^{2+}$ - and the cAMP-dependent signaling pathways. ${ }^{8,9,11,14-16}$ These two signaling pathways regulate both small $\left(\mathrm{IP}_{3} / \mathrm{Ca}^{2+}\right)$ and large (cAMP) cholangiocyte growth/loss in rodent models of cholestasis. ${ }^{8,9,11,14-16}$

Histamine is derived from the conversion of histidine to histamine through the enzyme L-histidine decarboxylase, ${ }^{17}$ and interacts with four $\mathrm{G}$ protein-coupled receptors: H1HR, H2HR, H3HR and H4HR. ${ }^{18,19}$ Although endogenous histamine elicits a proliferative effect in different cell types, ${ }^{20,21}$ the four histamine receptors (HRs) interact with independent $G$ proteins to stimulate varying signaling pathways producing varying effects on cells. ${ }^{22}$ The H1HR couples to $G \alpha_{\mathrm{q}}$ mobilizing $\mathrm{Ca}^{2+}$-dependent signaling in a number of cells including cholangiocytes, ${ }^{15,22}$ whereas the H2HR mainly interacts with $\mathrm{G} \alpha_{\mathrm{s}}$ stimulating a cAMP-dependent pathway. ${ }^{23}$ These two receptors stimulate the growth of numerous cell types, including cholangiocytes. ${ }^{15,21}$ This is in contrast to $\mathrm{H} 3$ and H4HRs that have inhibitory effects on cell growth (including cholangiocytes) ${ }^{16}$ by $\mathrm{G} \alpha_{\mathrm{i}}$ coupling that inhibits cAMP synthesis. ${ }^{16}$ In our study, we tested the hypotheses that (1) histamine stimulates cholangiocyte proliferation of normal rats and (2) an H1HR agonist stimulates the proliferation of small cholangiocytes by activation of $\mathrm{IP}_{3} / \mathrm{Ca}^{2+}$ signaling, whereas $\mathrm{H} 2 \mathrm{HR}$ agonists increase the proliferation of large cholangiocytes by an intracellular mechanism requiring the activation of cAMP-dependent signaling.

\section{MATERIALS AND METHODS Materials}

Reagents were purchased from Sigma Chemical (St Louis, $\mathrm{MO})$, unless otherwise indicated. The HR agonists, histamine trifluoromethyl toluidide (HTMT dimaleate, H1HR agonist), ${ }^{15}$ amthamine dihydrobromide (H2HR agonist $)^{24}$ and $(\mathrm{R})-(\alpha)-(-)$-methylhistamine dihydrobromide (RAMH, a H3HR agonist) ${ }^{16}$ were obtained from Tocris Bioscience (Ellisville, MO). The monoclonal mouse antibody against proliferating cellular nuclear antigen (PCNA, clone PC10, cat. no. M0879) was purchased from Dako (Kyoto, Japan). The substrate for $\gamma$-glutamyl transpeptidase $(\gamma$-GT), $N$ - $(\gamma$-Lglutamyl)-4-methoxy-2-naphthylamide was purchased from Polysciences (Warrington, PA). Antibodies for HR subtypes were purchased from Santa Cruz Biotechnology (Santa Cruz,
CA), and previously used in rat liver sections and in rat and mouse cholangiocytes. ${ }^{15,16}$ In particular, H1HR (clone A-20, cat. no. sc-33970) is an affinity-purified goat polyclonal antibody raised against a peptide mapping within a cytoplasmic domain of H1HR of human origin. H2HR (clone $\mathrm{H}-70$, cat. no. sc-50314) is a rabbit polyclonal antibody raised against amino acids 290-359 mapping within a C-terminal cytoplasmic domain of $\mathrm{H} 2 \mathrm{HR}$ of human origin. H3HR (clone C-20, cat. no. sc-17921) is an affinity-purified goat polyclonal antibody raised against a peptide mapping near the $\mathrm{C}$ terminus of H3HR of human origin. H4HR (clone Q-20, cat. no. sc-33965) is an affinity-purified goat polyclonal antibody raised against a peptide mapping within a cytoplasmic domain of H4HR of human origin. The goat polyclonal affinity-purified phosphorylated-PKC $\alpha$ antibody (Ser 657, cat. no. sc-12356) was raised against a short aminoacid sequence containing phosphorylated Ser 657 of PKC $\alpha$ of human origin (Santa Cruz Biotechnology). PKC $\alpha$ (H-7, sc-8393) is a mouse monoclonal antibody specific for an epitope mapping between amino acids 645 and 672 at the $\mathrm{C}$ terminus of PKC $\alpha$ of human origin (Santa Cruz Biotechnology). The goat polyclonal affinity-purified pPKA II $\alpha$ reg antibody (Ser 96, sc-12905-R) was raised against a short amino-acid sequence containing phosphorylated Ser 96 of p-PKA II $\alpha$ reg of human origin (Santa Cruz Biotechnology). The PKA $\alpha$ cat affinity-purified rabbit polyclonal antibody (C-20, sc-903, Santa Cruz Biotechnology) against total PKA was raised against a peptide mapping at the $\mathrm{C}$ terminus of PKA $\alpha$ cat of human origin. The RNeasy mini kit to purify total RNA from cholangiocytes was purchased from Qiagen (Valencia, CA). The RIA kits for measurement of intracellular cAMP ([$\left.{ }^{125} \mathrm{I}\right]$ Biotrak Assay System, RPA509) and $\mathrm{IP}_{3}$ (D-myo-inositol 1,4,5-trisphosphate $\left(\mathrm{IP}_{3}\right)\left[{ }^{3} \mathrm{H}\right]$ Biotrak Assay System, TRK1000) levels were purchased from GE Healthcare (Piscataway, NJ).

\section{Experimental Models}

Male Fisher rats (weighing 150-175 g) were purchased from Charles River (Wilmington, MA) and maintained in a temperature-controlled environment $\left(20-22^{\circ} \mathrm{C}\right)$ with $12: 12$-h light-dark cycles. Animals were fed ad libitum standard chow and had free access to drinking water. Our studies were performed in normal rats treated by daily IP injections with vehicle $(0.9 \% \mathrm{NaCl})$, histamine $(0.5 \mathrm{mg} / \mathrm{kg}$ of $\mathrm{BW}),{ }^{25}$ HTMT dimaleate (H1HR agonist, $0.5 \mathrm{mg} / \mathrm{kg}$ of BW), ${ }^{26}$ amthamine dihydrobromide (H2HR agonist, $0.5 \mathrm{mg} / \mathrm{kg}$ of BW), ${ }^{27}$ RAMH (H3HR agonist, $10 \mathrm{mg} / \mathrm{kg}$ of BW $)^{16}$ or the H4HR agonist, clobenpropit $(10 \mathrm{mg} / \mathrm{kg} \text { of BW })^{28}$ for 1 week. Before each experimental procedure, animals were injected with sodium pentobarbital $(50 \mathrm{mg} / \mathrm{kg}$ weight, IP). Study protocols were performed in compliance with the institutional guidelines set forth by the Institutional Animal Care and Use Committee (Scott and White Texas A\&M Health Science Center). 


\section{Purified Cholangiocytes and Normal Rat Intrahepatic Cholangiocyte Cultures}

Virtually pure cholangiocytes were isolated by immunoaffinity separation ${ }^{13,16,29}$ with a monoclonal antibody (a gift from Dr R Faris) against an unidentified antigen expressed by all intrahepatic rat cholangiocytes. ${ }^{29}$ Cell count and viability $(\sim 97 \%)$ were measured by trypan blue exclusion. Purity $(\sim 99 \%)$ was assessed by histochemistry for $\gamma-\mathrm{GT}^{30}$ The in vitro experiments were performed in freshly isolated cholangiocytes and our polarized normal rat intrahepatic cholangiocyte culture (NRICs). ${ }^{31}$ Cell number and frequency distribution of NRIC were measured using an automated cell counter (Cellometer Auto T4, Nexcelom Bioscience). ${ }^{32}$

\section{Assessment of Histamine Receptor Expression}

We evaluated the expression of HR subtypes by (1) immunohistochemistry ${ }^{15,33}$ in normal liver sections; (2) immunofluorescence ${ }^{15}$ in NRIC smears; and (3) RT-PCR ${ }^{15}$ ( $1 \mu \mathrm{g}$ total RNA) and immunoblots (10 $\mu \mathrm{g}$ protein) from freshly isolated normal cholangiocytes and NRICs. Immunohistochemistry in liver sections with the selected HR antibodies (1:100 dilution) was performed as described previously. ${ }^{15,16}$ For all immunoreactions, negative controls (with pre-immune serum substituted for the primary antibody) were included. Light microscopy photographs of liver sections were taken by Leica Microsystems DM 4500 B Light Microscopy (Leica Microsystems, Weltzlar, Germany) using a Jenoptik Prog Res C10 Plus Videocam (Jena, Germany). Immunofluorescence for HR subtypes in NRICs was performed as described previously. ${ }^{15}$ After staining, images were visualized using a confocal microscope (Olympus IX-71; Olympus, Tokyo, Japan). For all immunoreactions, appropriate negative controls were used.

Standard RT-PCR conditions were used for measurement of the mRNA expression for $\mathrm{H} 1-\mathrm{H} 4 \mathrm{R}$ in pooled cholangiocytes (formed by small and large cholangiocytes) ${ }^{31}$ and NRICs: $10 \mathrm{~min}$ at $95^{\circ} \mathrm{C}, 15 \mathrm{~s}$ at $95^{\circ} \mathrm{C}, 30 \mathrm{~s}$ at $55^{\circ} \mathrm{C}$ and $30 \mathrm{~s}$ at $72^{\circ} \mathrm{C}, 30$ cycles at $4^{\circ} \mathrm{C}$. Specific primers designed against the rat H1HR (NM_000861, expected fragment length $157 \mathrm{bp}$ ), H2HR (NM_022304, expected fragment length 181 bp), H3HR (NM_053506, expected fragment length $180 \mathrm{bp}$ ), H4HR (NM_131909, expected fragment length $181 \mathrm{bp}$ ) and glyceraldehyde-3-phosphate dehydrogenase (GAPDH, NM_002046, the housekeeping gene, ${ }^{34}$ expected fragment length $175 \mathrm{bp}$ ) were purchased from (SABiosciences, Frederick, MD). We used RNA from the rat brain and water as positive and negative controls, respectively. The protein expression of $\mathrm{H} 1-\mathrm{H} 4 \mathrm{HR}$ was measured by immunoblots in protein $(10 \mu \mathrm{g})$ lysates from the brain (positive control) and isolated small and large normal cholangiocytes. Immunoblots were normalized by $\beta$-actin. ${ }^{15,16}$

\section{In Vivo Studies Evaluation of the Intrahepatic Bile Duct Mass of Small, Large and Pooled Ducts}

In the selected groups of animals, cholangiocyte growth was measured in liver sections ( $4 \mu \mathrm{m}$ thick) by evaluation of the percentage of intrahepatic small, large and pooled bile ducts stained for cytokeratin-19 (CK-19, a specific marker of the biliary epithelium). ${ }^{9,34}$ In each liver section, IBDM was measured as area occupied by CK-19-positive bile duct/total area $\times 100 .^{35}$ Sections were analyzed using a BX-51 light microscope (Olympus) with a video cam (Spot Insight; Diagnostic Instrument Inc., Sterling Heights, MI) and processed using an Image Analysis System (IAS: Delta Sistemi, Rome, Italy).

Cholangiocyte proliferation was also evaluated by immunoblots for PCNA ${ }^{14}$ in protein $(10 \mu \mathrm{g})$ lysates from the spleen (positive control) and isolated cholangiocytes from the selected experimental groups. Immunoblots were normalized by $\beta$-actin. ${ }^{15,16}$ Band intensity was determined by scanning video densitometry using the phospho-imager, Storm 860 (GE Healthcare) and the ImageQuant TL software version 2003.02 (GE Healthcare, Little Chalfont, Buckinghamshire, England).

\section{Effect of In Vivo Administration of Histamine on Basal- and Secretin-Stimulated Bile and Bicarbonate Secretion and CAMP levels}

We measured the effect of chronic in vivo administration of histamine to normal rats on basal- and secretin-stimulated bile secretion (in bile fistula rats) ${ }^{3,9}$ and cAMP levels (in purified cholangiocytes), ${ }^{13,14,16}$ two functional parameters of cholangiocyte proliferation. ${ }^{3,9,13,14}$ After anesthesia, rats were surgically prepared for bile collection as described previously. ${ }^{3,9}$ When steady-state bile flow was reached (60-70 min from the intravenous infusion of Krebs-RingerHenseleit solution, KRH), rats were infused with secretin $(100 \mathrm{nM})$ for $30 \mathrm{~min}$, followed by intravenous infusion of $\mathrm{KRH}$ for $30 \mathrm{~min}$. Bicarbonate concentration in bile was determined using an ABL 520 Blood Gas System (Radiometer Medical A/S, Copenhagen, Denmark).

After purification, cholangiocytes $\left(1 \times 10^{5}\right.$ cells $)$ were incubated at $37^{\circ} \mathrm{C}$ for $1 \mathrm{~h}$ (to regenerate membrane proteins damaged by proteolytic enzymes during cell isolation $)^{5}$ and subsequently stimulated at room temperature for $5 \mathrm{~min}$ with $0.2 \%$ bovine serum albumin (BSA) or secretin (100 nM solution containing $0.2 \%$ BSA) before evaluation of cAMP levels by RIA. ${ }^{13,14,16}$

\section{In Vitro Studies Evaluation of Cholangiocyte Proliferation and Signaling Mechanisms}

Effects of histamine, H1HR or H2HR agonists (in the absence or presence of specific HR antagonists or inhibitors of $\mathrm{IP}_{3} / \mathrm{Ca}^{2+}$ or cAMP signaling) on cholangiocyte proliferation and signaling mechanisms were evaluated in NRICs. ${ }^{31}$ To evaluate dose and time dependency, NRICs were treated with $0.2 \%$ BSA (basal) or histamine $(10,50$ and $100 \mu \mathrm{M})$ for 24 and $48 \mathrm{~h}$ before evaluating cell proliferation using the CellTiter 96 Aqueous One Solution Cell Proliferation Assay (MTS) ${ }^{15}$ (see above). In separate sets of experiments, NRICs were treated at $37^{\circ} \mathrm{C}$ for $24 \mathrm{~h}$ with: (1) $0.2 \% \mathrm{BSA}$; (2) 
histamine $(10 \mu \mathrm{M})$ in the absence or presence of preincubation with terfenadine (H1HR antagonist, $10 \mu \mathrm{M}),{ }^{15}$ or cimetidine (H2HR antagonist, $10 \mu \mathrm{M})^{36}$ or terfenadine + cimetidine (both at $10 \mu \mathrm{M}+$ histamine, $10 \mu \mathrm{M}$ ); or (3) HTMT dimaleate (H1HR agonist, $10 \mu \mathrm{M}),{ }^{15}$ amthamine dihydrobromide (H2HR agonist, $10 \mu \mathrm{M}),{ }^{37}$ RAMH (H3HR agonist, $10 \mu \mathrm{M})^{16}$ or clobenpropit (H4HR agonist, $\left.10 \mu \mathrm{M}\right)^{37}$ before evaluation of proliferation by MTS assays. ${ }^{15}$ To determine whether the stimulatory effects of histamine (the endogenous neurotransmitter) on NRIC proliferation are mediated by activation of $\mathrm{H} 1$ (mediated by $\mathrm{Ca}^{2+}$ signaling) and/or H2 (regulated by cAMP signaling) HRs, we stimulated NRICs at $37^{\circ} \mathrm{C}$ for $24 \mathrm{~h}$ with (1) $0.2 \% \mathrm{BSA}$; (2) histamine $(10 \mu \mathrm{M})$; or (3) HTMT dimaleate $(10 \mu \mathrm{M}),{ }^{15}$ or amthamine dihydrobromide $(10 \mu \mathrm{M})^{37}$ in the absence or presence of preincubation with BAPTA/AM $(5 \mu \mathrm{M}),{ }^{15}$ Gö6976 $\left(1 \mu \mathrm{M}, \mathrm{Ca}^{2+}\right.$. dependent PKC $\alpha$ inhibitor $)^{38}$ or Rp-cAMPs $(100 \mu \mathrm{M}$, PKA inhibitor). ${ }^{13}$

\section{Measurement of $\mathrm{IP}_{3}$ and CAMP Levels and Phosphorylation of PKC and PKA}

We performed experiments in NRICs aimed to demonstrate that HTMT dimaleate increases $\mathrm{IP}_{3}$ levels and PKC phosphorylation, whereas amthamine dihydrobromide enhances cAMP levels and PKA phosphorylation. For evaluation of cAMP levels, NRICs were treated at room temperature for $5 \min ^{5,13}$ with (1) $0.2 \%$ BSA or (2) HTMT dimaleate $(10 \mu \mathrm{M})^{15}$ or amthamine dihydrobromide $(10 \mu \mathrm{M})$ before evaluation of cAMP levels by RIA.,13 For measurements of $\mathrm{IP}_{3}$ levels, NRICs were treated at room temperature for 10 min with (1) $0.2 \%$ BSA or (2) HTMT dimaleate $(10 \mu \mathrm{M})^{15}$ or amthamine dihydrobromide $(10 \mu \mathrm{M})$ before evaluation of $\mathrm{IP}_{3}$ levels by RIA. ${ }^{15}$

Before evaluation of phosphorylation of PKC or PKA, ${ }^{39}$ NRICs were treated at room temperature for 90 min with (1) $0.2 \%$ BSA or (2) HTMT dimaleate $(10 \mu \mathrm{M})^{15}$ or amthamine dihydrobromide $(10 \mu \mathrm{M}){ }^{37}$

\section{Effect of PKC $\alpha$ Silencing on NRIC Proliferation}

As (1) $\mathrm{IP}_{3} / \mathrm{Ca}^{2+}$-dependent $\mathrm{PKC} \alpha$ has a key role in the regulation of cholangiocyte functions ${ }^{14,39,40}$ and (2) HTMT dimaleate increases $\mathrm{IP}_{3}$ levels and $\mathrm{PKC} \alpha$ phosphorylation (see the 'Results' section), we evaluated the effect of PKC $\alpha$ silencing on NRIC proliferation after treatment of these cells with HTMT dimaleate. NRICs were plated into 6-well plates and allowed to adhere overnight. siRNA transfection (0.25$1 \mu \mathrm{g}$ of PKC $\alpha$ siRNA was used) was performed according to the instructions provided by Santa Cruz Biotechnology. Diluted siRNA duplexes were added to the cells and allowed to incubate for $5 \mathrm{~h}$ at $37^{\circ} \mathrm{C}$ in a $\mathrm{CO}_{2}$ incubator. For controls, a scrambled siRNA duplex (Santa Cruz Biotechnology) was added to corresponding wells. The extent of $\mathrm{PKC} \alpha$ silencing was evaluated by measuring the protein expression of total PKC $\alpha$ in transfected $v s$ control NRICs by immunoblots (see above). ${ }^{15}$ PCNA protein expression was evaluated in NRIC cells treated with $0.2 \%$ BSA or HTMT dimaleate $(10 \mu \mathrm{M})$ for $24 \mathrm{~h}$ in the absence or presence of PKC $\alpha$ siRNA $(1.0 \mu \mathrm{g})$.

\section{Statistical Analysis}

All data are expressed as mean \pm s.e.m. Differences between groups were analyzed by Student's unpaired $t$-test when two groups were analyzed and ANOVA when more than two groups were analyzed, followed by an appropriate post hoc test.

\section{RESULTS}

\section{Histamine Receptor Expression}

By immunohistochemistry in liver sections, both small (yellow arrow) and large (red arrow) bile ducts express the four HR subtypes (H1-H4HRs) (Figure 1a). By immunofluorescence, NRICs (which are formed by small and large cholangiocytes as evaluated by frequency size distribution $)^{31}$ (Figure 1b) expressed the four HRs (Figure 1b). DAPI staining is seen in blue, whereas the red staining represents the specific HR. A merged image is also supplied along with negative staining (Figure 1b). By RT-PCR, purified pooled (containing small and large cells) cholangiocytes from normal rats and NRICs expressed H1-H4HRs (Figure 1c). In addition, by immunoblots, purified small and large normal cholangiocytes expressed H1-H4HRs (Figure 1c).

\section{Evaluation of Intrahepatic Bile Duct Mass}

Chronic administration of histamine and the H1HR agonist, HTMT dimaleate, increased small IBDM of normal rats compared with saline-treated rats (Figure 2a); the H2HR agonist, amthamine dihydrobromide, did not alter small IBDM (Figure 2a). Histamine and amthamine dihydrobromide (but not HTMT dimaleate) increased large IBDM of normal rats compared with control rats (Figure 2b). Histamine, the $\mathrm{H} 1$ and the H2HRs agonists increased overall IBDM (Figure $2 \mathrm{a}-\mathrm{c}$ ). No changes were observed when normal rats were treated with RAMH or clobenpropit (not shown). There was a significant increase in PCNA protein expression in freshly isolated pooled cholangiocytes from normal rats treated with histamine, $\mathrm{H} 1 \mathrm{HR}$ or $\mathrm{H} 2 \mathrm{HR}$ agonists compared with vehicle-treated rats (Figure 2d). These results rule out the potential role of the $\mathrm{H} 3 \mathrm{HR}$ and $\mathrm{H} 4 \mathrm{HR}$ agonists in activating cholangiocyte proliferation.

\section{Effect of In Vivo Administration of Histamine on Basal- and Secretin-Stimulated Bile and Bicarbonate Secretion and CAMP Levels}

Secretin increased intracellular cAMP levels in cholangiocytes from normal rats treated with saline (Figure 3). Chronic in vivo administration of histamine to normal rats increased both basal- and secretin-stimulated cAMP levels of cholangiocytes (a functional index of biliary growth) $)^{3,11,14}$ compared with their corresponding values of purified cholangiocytes from saline-treated normal rats (Figure 3). As previously shown, ${ }^{3}$ intravenous infusion of secretin did not 
increase bile and bicarbonate secretion in normal rats (Table 1). Secretin increased bile and bicarbonate secretion in normal rats treated with histamine compared with normal rats treated with saline (Table 1), demonstrating that histamine stimulates biliary hyperplasia by activation of cAMPdependent signaling.

\section{In Vitro Studies Evaluation of Cholangiocyte Proliferation and Signaling Mechanisms}

Dose- and time-response experiments demonstrated that histamine increases NRIC proliferation (by MTS assays) compared with BSA-treated NRICs (Figure 4). As the stimulatory effects of histamine on cholangiocyte proliferation were seen as early as after $24 \mathrm{~h}$ of incubation, all other stimulations were performed at $24 \mathrm{~h}$ at the histamine concentration of $10 \mu \mathrm{M}$, the smallest dose at which we observed a stimulatory effect on NRIC proliferation. Furthermore, we performed experiments aimed to demonstrate which HR subtypes regulate histamine-stimulated NRIC proliferation. Histamine, H1HR and H2HR (but not H3HR or H4HR) agonists increased NRIC proliferation (Figure 5a). Histamine stimulation of NRIC proliferation was blocked by terfenadine
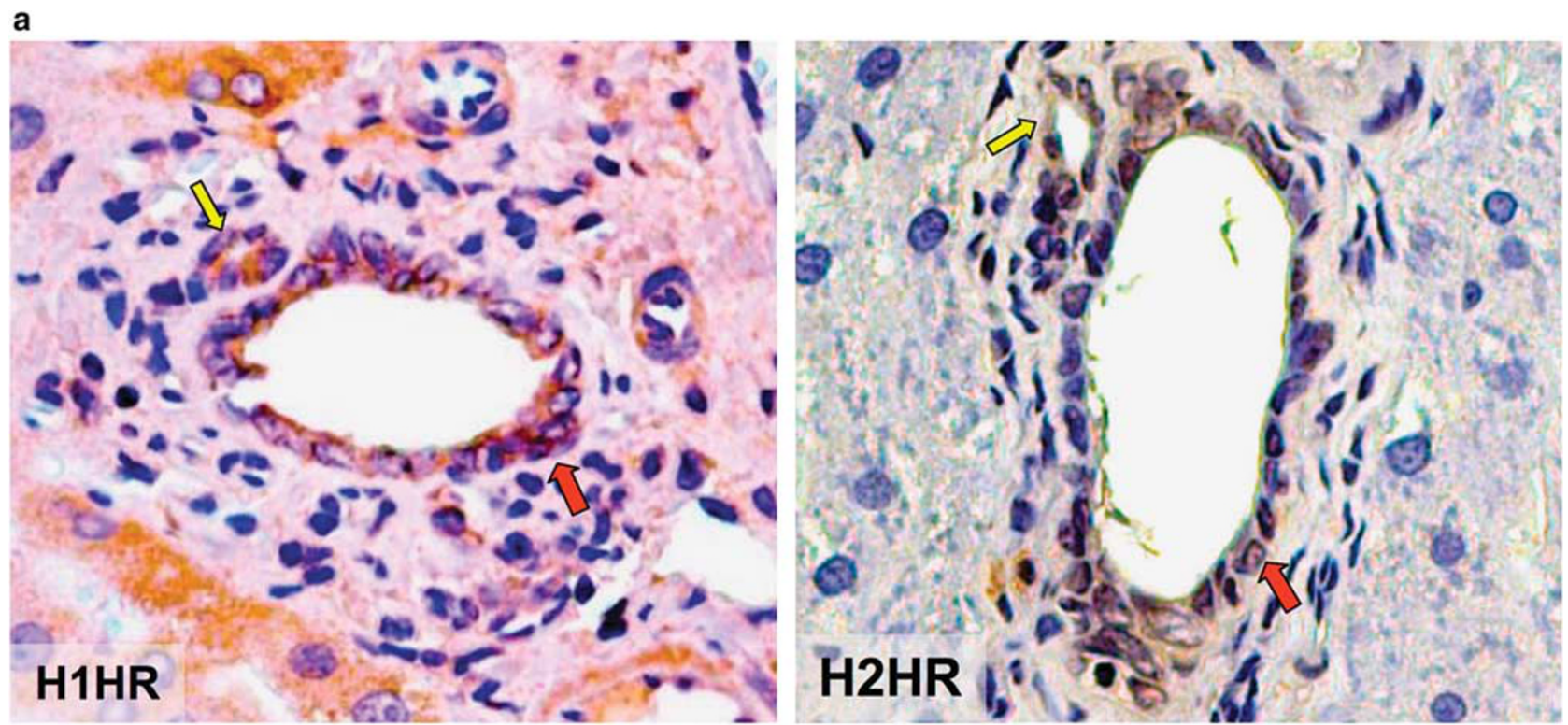

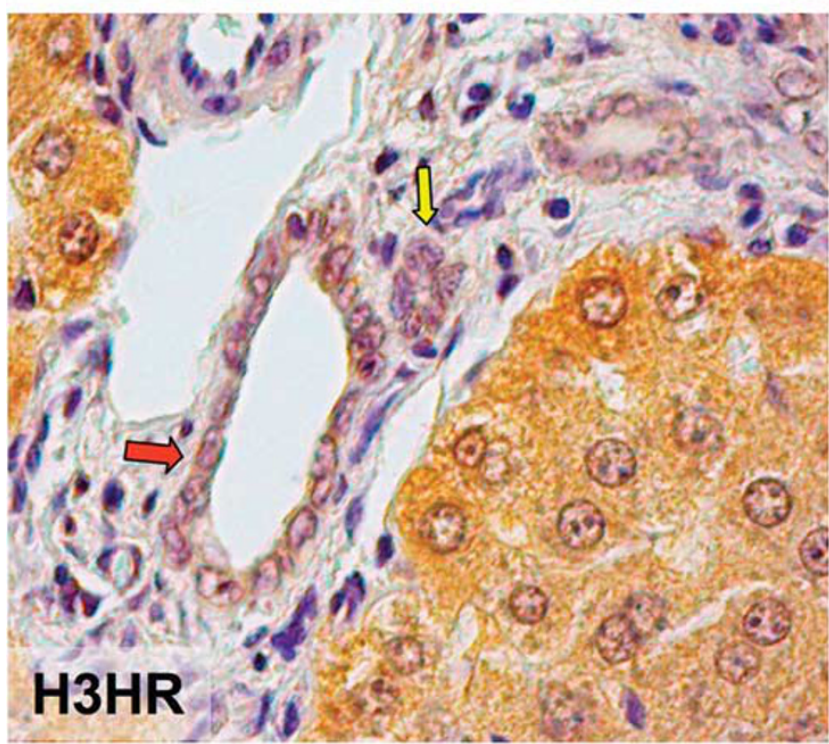

$\Rightarrow$ Large ducts

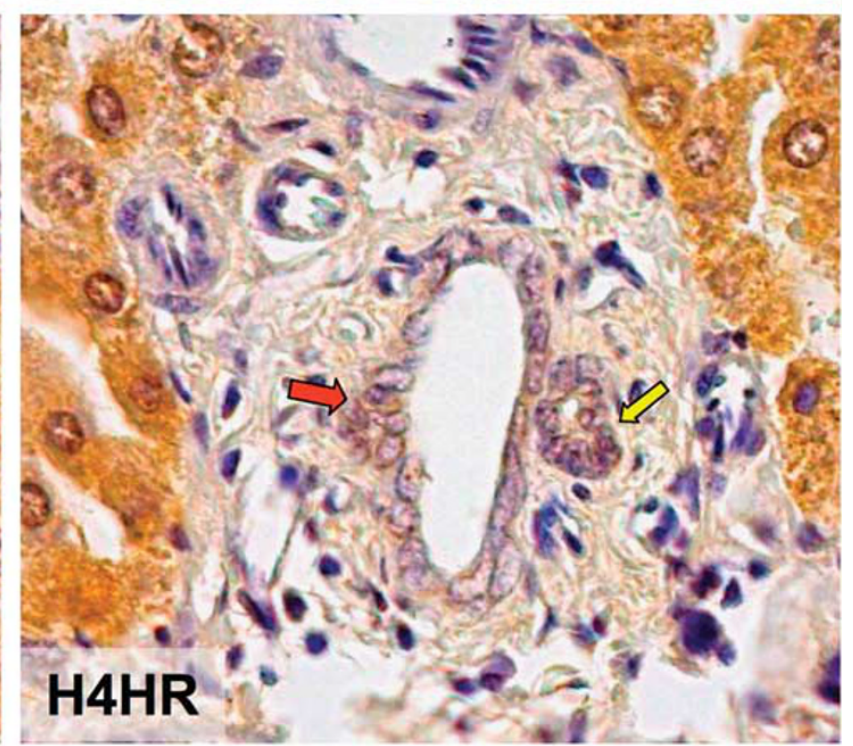

$\Rightarrow$ Small ducts

Figure 1 (a) By immunohistochemistry in liver sections, both small (yellow arrow) and large (red arrow) bile ducts express H1-H4HRs. Original magnification $\times 40$. (b) Frequency size distribution shows that NRIC are formed by both small and large NRICs. NRIC by immunofluorescence (bar $=20 \mu \mathrm{m}$ ); DAPI staining is seen in blue, whereas the red staining represents the specific histamine receptor. A merged image is shown along with negative staining. (c) By RT-PCR, purified pooled cholangiocytes from normal rats and NRICs expressed $H 1-H 4 H R$. By immunoblots, purified small and large normal cholangiocytes expressed $\mathrm{H} 1-\mathrm{H} 4 \mathrm{HRs}$. 


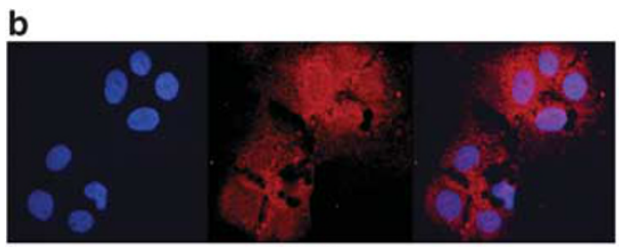

$\mathrm{H} 1 \mathrm{HR}$

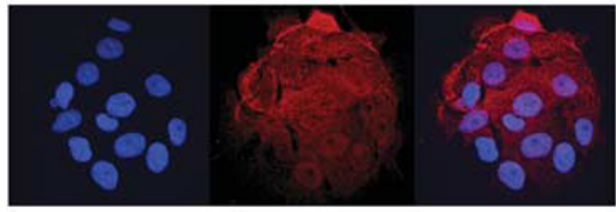

H2HR

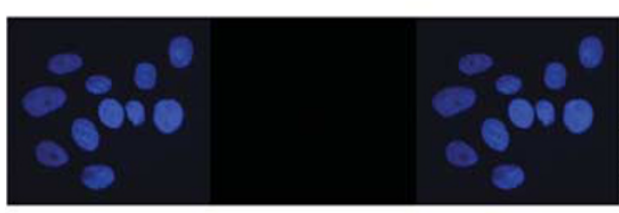

Negative

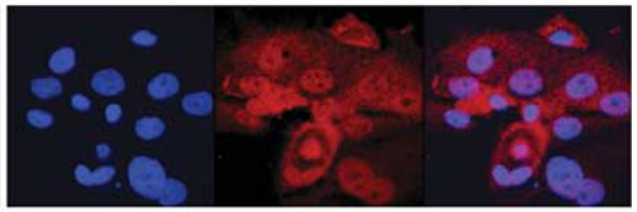

H3HR

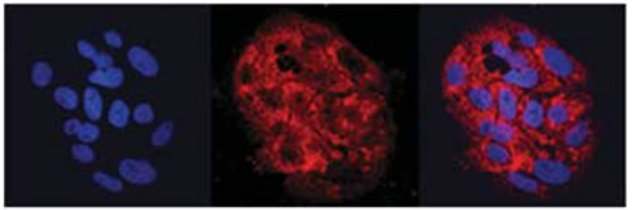

$\mathrm{H} 4 \mathrm{HR}$

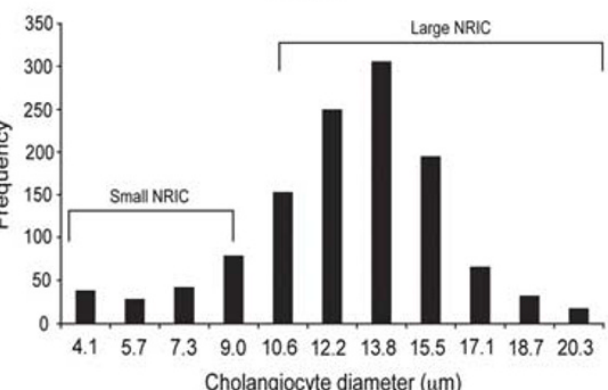

C
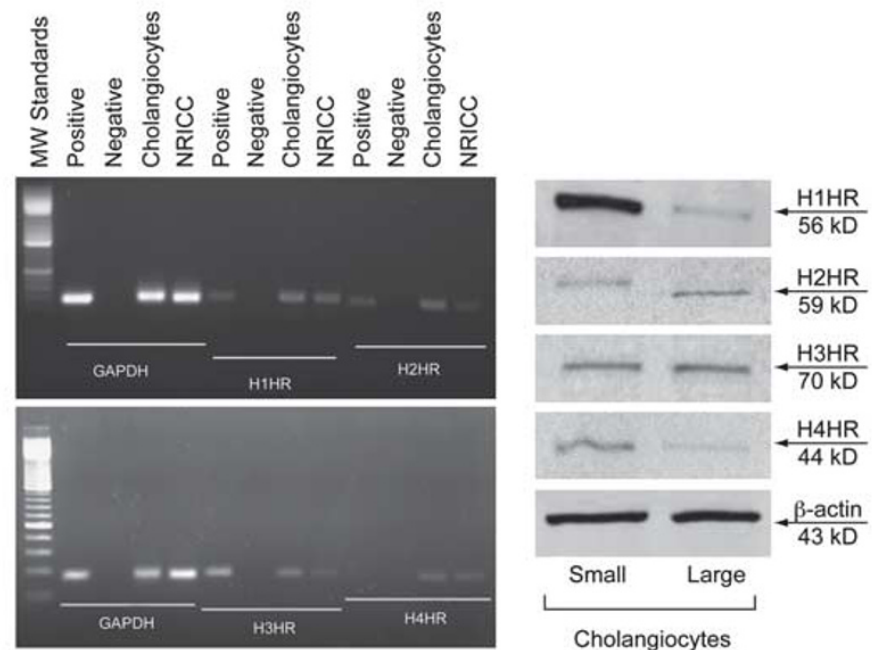

Figure 1 Continued.

(H1HR antagonist), cimetidine (H2HR antagonist) and at the same extent by terfenadine + cimetidine (Figure 5a), demonstrating that both H1HR (by activation of $\mathrm{Ca}^{2+}$ signaling; see Figure 6) and H2HR (by activation of cAMP signaling; see Figure 6) mediate histamine-induced increase in NRIC proliferation (Figure 5a). Furthermore, we demonstrated that (1) H1HR and H2HR (in addition to histamine) agonists stimulate NRIC proliferation (Figure $5 \mathrm{~b}$ and c); (2) H1HR-induced NRIC proliferation was blocked by BAPTA/ AM and Gö6976 but not by Rp-cAMPs (Figure 5b); and (3) H2HR-induced NRIC proliferation was blocked by Rp-cAMPs but not BAPTA/AM and Gö6976 (Figure 5c).
Measurement of $\mathrm{IP}_{\mathbf{3}}$ and CAMP Levels and PKC and PKA We demonstrated that HTMT dimaleate (H1HR agonist) increases $\mathrm{IP}_{3}$ levels (Figure 6a) and PKC phosphorylation (Figure 6c), whereas amthamine dihydrobromide (H2HR agonist) enhances cAMP levels (Figure 6b) and PKA phosphorylation (Figure 6d). HTMT dimaleate did not alter cAMP levels of NRIC, whereas amthamine dihydrobromide did not change $\mathrm{IP}_{3}$ levels of NRIC (Figure $6 \mathrm{a}$ and $\mathrm{b}$ ).

\section{Effect of PKC $\alpha$ Silencing on NRIC Proliferation}

With the finding that the H1HR agonist increased phosphorylation of $\mathrm{PKC} \alpha$, we sought to pinpoint the role of 
$\mathrm{Ca}^{2+}$-dependent $\mathrm{PKC} \alpha$ (that has a key role in biliary growth) ${ }^{14,39-44}$ on NRICs (after stimulation with HTMT dimaleate) using siRNA transfection. In PKC $\alpha$-siRNA $(1.0 \mu \mathrm{g})$-transfected cells $(90 \%$ knockdown efficiency,
Figure 7a), HTMT dimaleate failed to increase NRIC proliferation (Figure 7b). As expected, in scrambled-transfected NRICs, HTMT dimaleate increased NRIC proliferation (Figure 7b).
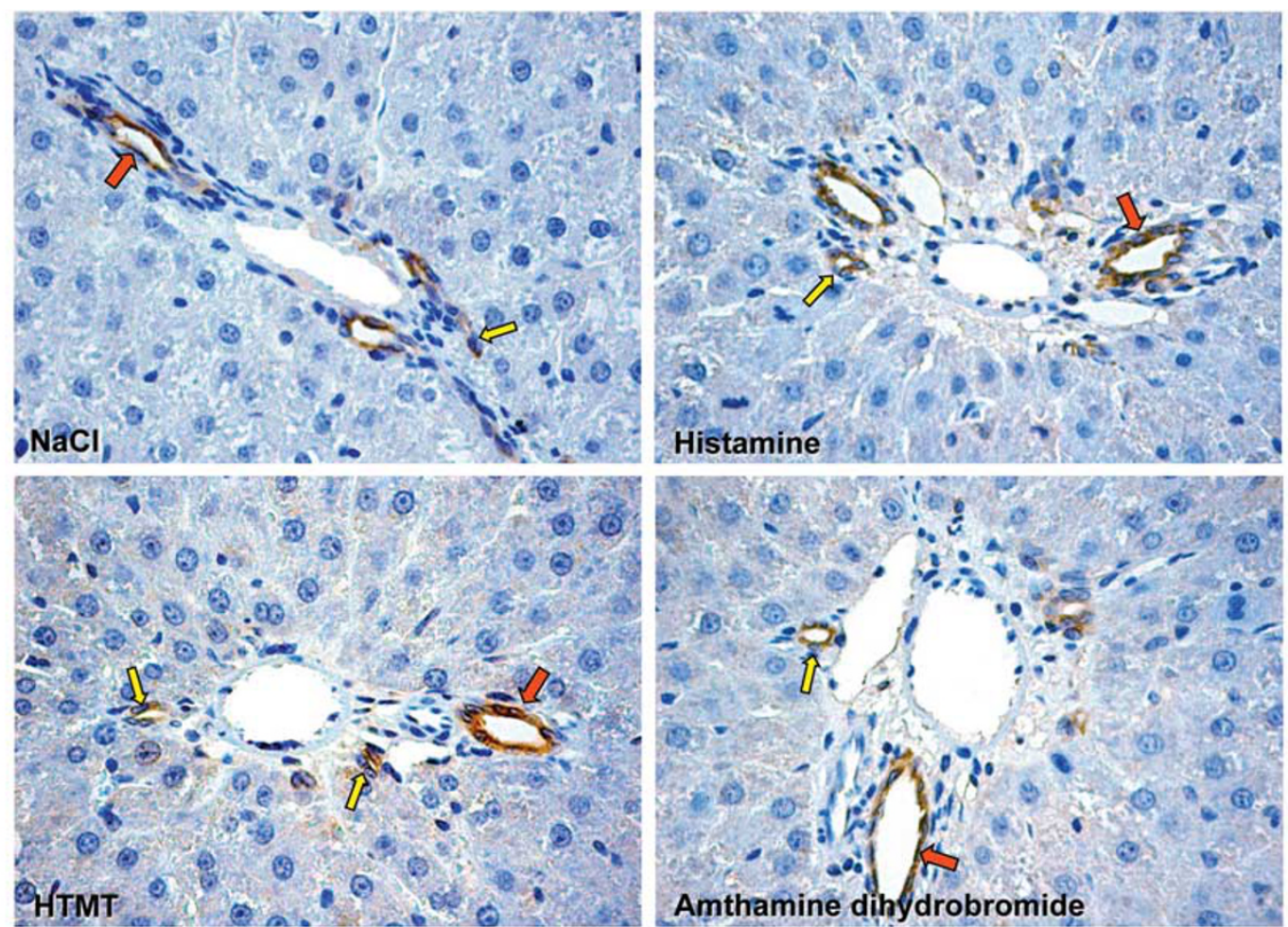

a

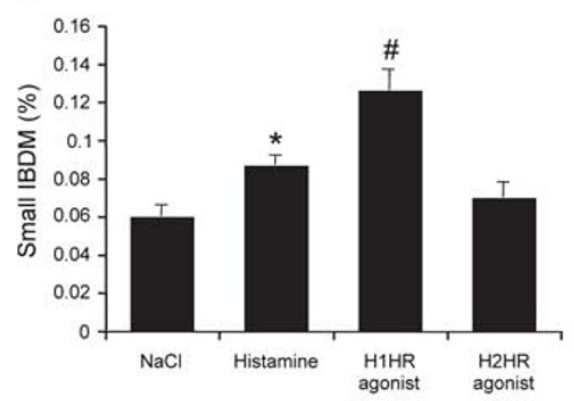

b

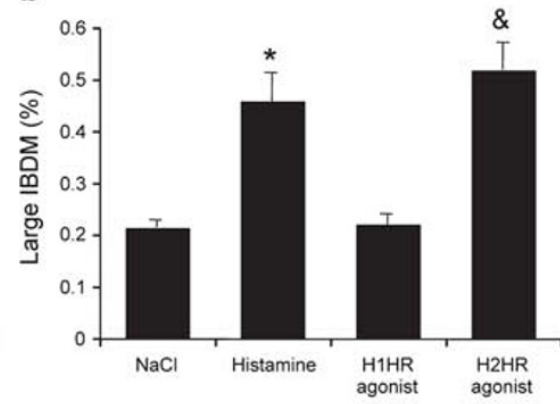

c

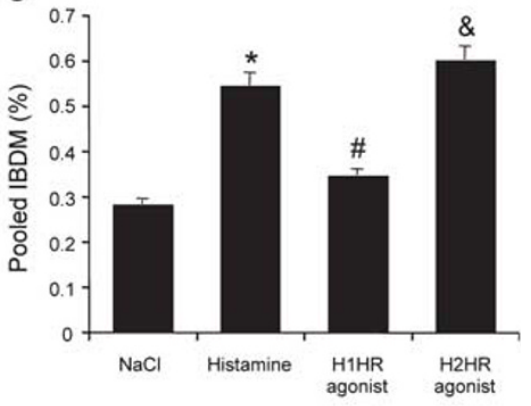

d

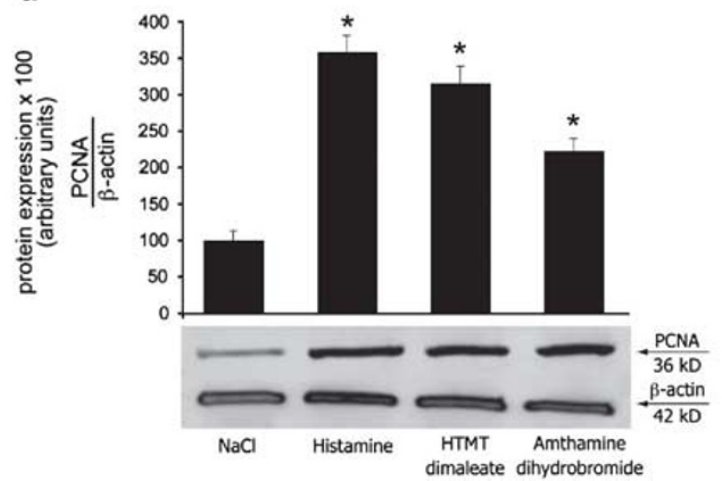




\section{DISCUSSION}

We have demonstrated that intrahepatic bile ducts, freshly isolated cholangiocytes and NRICs express H1-H4HRs. We have shown that histamine increases normal cholangiocyte growth by interaction with H1HR and H2HR by activation of both $\mathrm{IP}_{3} / \mathrm{Ca}^{2+}$ - and cAMP-dependent mechanisms, respec-

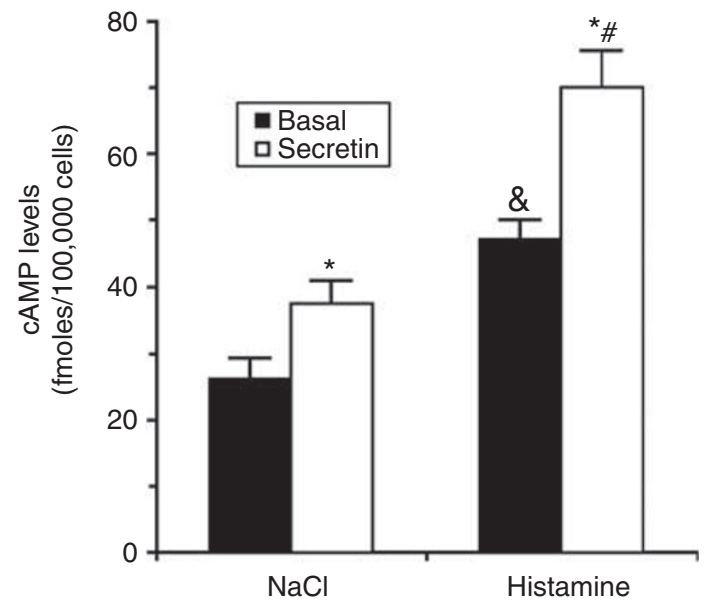

Figure 3 Evaluation of basal- and secretin-stimulated cAMP levels in purified cholangiocytes from normal rats treated with saline or histamine for 1 week. Histamine increased both basal- and secretin-stimulated cAMP of normal cholangiocytes compared with cholangiocytes from normal rats treated with saline. ${ }^{\circledR} P<0.05$ vs basal cAMP levels of cholangiocytes from normal rats treated with saline. ${ }^{*} P<0.05$ vs basal cAMP levels of cholangiocytes from saline-treated normal rats. ${ }^{\#} P<0.05$ vs secretinstimulated cAMP levels of cholangiocytes from saline-treated normal rats. Data are mean \pm s.e.m. of six experiments. tively. Furthermore, the H1HR agonist increases NRIC proliferation by activation of $\mathrm{IP}_{3} / \mathrm{Ca}^{2+} / \mathrm{PKC} \alpha$-dependent signaling likely targeting small $\mathrm{Ca}^{2+}$-dependent NRIC. When PKC $\alpha$ was silenced, the H1HR agonist did not increase NRIC proliferation. In contrast, the H2HR (that signals through activation of $\left.\mathrm{G} \alpha_{\mathrm{s}}\right)^{23}$ induces normal cholangiocyte growth by activation of a cAMP/PKA-dependent mechanism (independent of PKC $\alpha$ ) by likely targeting large cAMP-dependent NRICs.

The finding that normal rat cholangiocytes and NRICs express $\mathrm{H} 1-\mathrm{H} 4 \mathrm{HR}$ are supported by previous studies in normal mouse ${ }^{15}$ and BDL rat cholangiocytes. ${ }^{16}$ Moreover, we have previously demonstrated the expression of $\mathrm{H} 3 \mathrm{HR}$ in hyperplastic cholangiocytes and cholangiocarcinoma cells, and defined the inhibitory role of H3HR in the growth of hyperplastic and neoplastic cholangiocytes. ${ }^{16,45}$ HRs are also expressed in the liver by hepatocytes that are activated by endogenous histamine to release a wide array of effects. ${ }^{46,47}$ For example, histamine activates $\mathrm{IP}_{3}$ synthesis in guinea pig hepatocytes by activation of $\mathrm{H}_{1} \mathrm{HR}^{47}$ and stimulates glycogenolysis in hepatocytes by interaction with H1HR by activating the $\mathrm{Ca}^{2+}$ messenger system. ${ }^{46}$

In animal models of cholangiocyte hyperplasia/loss, both $\mathrm{IP}_{3} / \mathrm{Ca}^{2+}$ - and cAMP-dependent signaling pathways regulate the proliferative activities of small and large cholangiocytes, respectively. ${ }^{3,8,9,16}$ For example, in the cholestatic BDL model, there is marked proliferation of large cholangiocytes by activation of cAMP signaling. ${ }^{3,8,16}$ With regard to $\mathrm{IP}_{3} /$ $\mathrm{Ca}^{2+}$-dependent signaling, stimulation of small cholangiocyte growth (eg, after feeding of the bile salt, taurocholate)

Table 1 Measurement of basal- and secretin-stimulated bile flow, bicarbonate concentration and secretion in normal rats treated with saline or histamine for 1 week

Bile flow

Treatment

$\begin{array}{cc}\text { Basal } & \text { Secretin } \\ (\mathrm{ml} / \mathrm{min} \text { per } \mathrm{kg} \mathrm{BW}) & (\mathrm{ml} / \mathrm{min} \text { per } \mathrm{kg} \mathrm{BW})\end{array}$

Bicarbonate secretion

\begin{tabular}{cc}
\hline $\begin{array}{c}\text { Basal } \\
\text { (mEquiv./min per kg BW) }\end{array}$ & $\begin{array}{c}\text { Secretin } \\
\text { (mEquiv./min per kg BW) }\end{array}$ \\
$2.3 \pm 0.2$ & $2.5 \pm 0.2$ \\
$2.4 \pm 0.2$ & $3.1 \pm 0.15^{*}$
\end{tabular}

\begin{tabular}{|c|c|c|c|c|}
\hline Normal rats $+\mathrm{NaCl}(n=7)$ & $68.3 \pm 6.2$ & $73.6 \pm 7.0$ & $2.3 \pm 0.2$ & $2.5 \pm 0.2$ \\
\hline Normal rats+histamine $(n=7)$ & $74.5 \pm 4.8$ & $90.5 \pm 5.2^{*}$ & $2.4 \pm 0.2$ & $3.1 \pm 0.15^{*}$ \\
\hline
\end{tabular}

BW, body weight.

When steady spontaneous bile flow was reached (60-70 min from the infusion of Krebs-Ringer-Henseleit (KRH), rats were infused for 30 min with secretin, followed by a final infusion of KRH for $30 \mathrm{~min}$. Data are mean \pm s.e.m. ${ }^{\star} P<0.05$ (by Student's unpaired $t$-test) $v s$ the corresponding basal value of bile flow or bicarbonate secretion of normal rats treated with histamine for 1 week.

Figure 2 (a-c) Effect of chronic administration of saline, histamine, H1HR or H2HR agonists on small, large and pooled IBDM of normal rats. (a) Administration of histamine and the H1HR agonist, HTMT dimaleate increased small IBDM of normal rats compared with saline-treated rats; the H2HR agonist, amthamine dihydrobromide, did not alter small IBDM. (b) Histamine and amthamine dihydrobromide (but not HTMT dimaleate) increased large IBDM of normal rats compared with control rats. (c) The IBDM of pooled bile ducts was increased by histamine and both $\mathrm{H} 1$ and $\mathrm{H} 2 \mathrm{HR}$ agonists. ${ }^{*} P<0.05$ vs small, large and pooled IBDM of normal rats. ${ }^{*} P<0.05$ vs small and pooled IBDM of normal rats. ${ }^{*} P<0.05$ vs large and pooled IBDM of normal rats. Data are mean \pm s.e.m. Ten randomly selected portal tracts were evaluated in three different slides. ${ }^{*} P<0.05$ vs IBDM of normal rats treated with saline. (d) There was a significant increase in PCNA protein expression in freshly isolated pooled cholangiocytes from normal rats treated with histamine, $\mathrm{H} 1 \mathrm{HR}$ or $\mathrm{H} 2 \mathrm{HR}$ compared with vehicle-treated rats. ${ }^{*} P<0.05$ vs PCNA of cholangiocytes from normal rats treated with saline. Data are mean \pm s.e.m. of four blots from several different and cumulative preparations of cholangiocytes. 
depends on the activation of the $\mathrm{Ca}^{2+}$-dependent PKC $\alpha{ }^{41}$ Moreover, activation of $\alpha 1$-adrenergic receptors stimulate the proliferation of small mouse cholangiocytes through $\mathrm{Ca}^{2+}$ dependent activation of NFAT2 and Sp1. ${ }^{48}$ In this study, we demonstrate that histamine stimulates small and large biliary growth by the differential activation of both $\mathrm{Ca}^{2+}$ and cAMP signaling. One possible explanation for the differential effects induced by histamine is likely due to the interaction with specific HRs expressed by different-sized cholangiocytes, ie, small and large. Indeed, we have shown that activation of H1HR increases the proliferation of small cholangiocytes by activation of $\mathrm{IP}_{3} / \mathrm{Ca}^{2+}$-CaMK I signaling. ${ }^{15}$ In addition, activation of $\mathrm{H} 3 \mathrm{HR}$ causes decreased large cholangiocyte hyperplasia by downregulation of cAMP-dependent signaling. ${ }^{16}$ Based on this, we propose that histamine-induced increases in the proliferation of both small and large cholangiocytes are mediated by activation of $\mathrm{IP}_{3} / \mathrm{Ca}^{2+}$ signaling in small

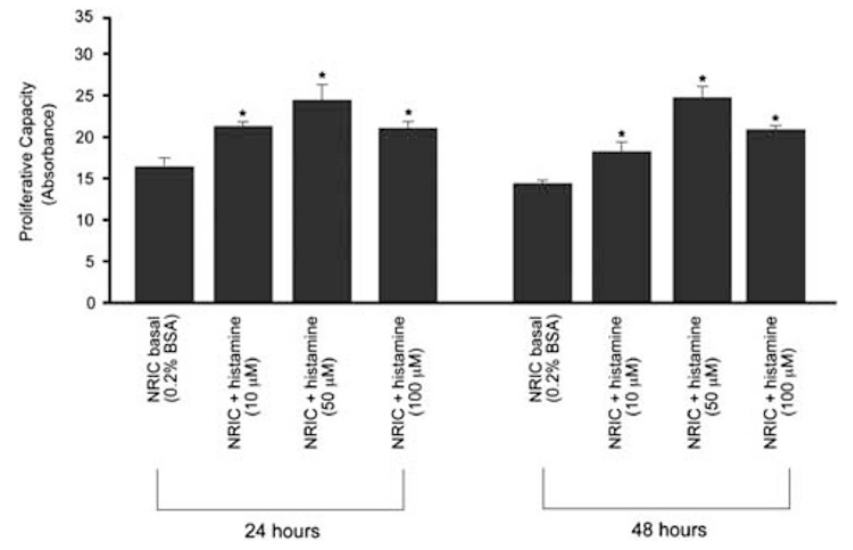

Figure 4 Dose- and time-response experiments demonstrated that histamine (at 10, 50 and $100 \mu \mathrm{M}$ ) increase NRIC proliferation (by MTS) compared with NRIC treated with BSA. ${ }^{*} P<0.05$ vs proliferation of NRIC treated in vitro with $0.2 \%$ BSA (basal). Data are mean \pm s.e.m. of seven experiments. cholangiocytes and NRICs (by likely interaction with H1HR) and cAMP transduction pathways in large cholangiocytes and NRICs (presumably mediated by H2HR). On the basis of this rationale and these previous findings, we also propose that the increase in secretin-stimulated choleresis (observed after in vivo administration of histamine to normal rats) likely depends on activation of H2HR in large cholangiocytes, the only biliary cell type in the liver that functions by a cAMPdependent mechanism. ${ }^{1,6,8,11}$

We next performed in vitro studies in polarized NRICs (which contain both small and large cholangiocytes, Figure 1b) and demonstrated that histamine activation of NRIC proliferation is blocked by terfenadine (H1HR antagonist), cimetidine (H2HR antagonist) and at the same extent by simultaneous treatment with terfenadine + cimetidine. A shortcoming of this in vitro experiment is represented by the fact that both H1HR and H2HR antagonists block completely the stimulatory effects of histamine on NRIC proliferation, although one of the two receptors (H1HR or $\mathrm{H} 2 \mathrm{HH}$ ) are still active during treatment with these two inhibitors. We provide this explanation supported by our previous findings. ${ }^{14,39,42,44,49,50}$ As we have previously demonstrated that cross-talk between $\mathrm{Ca}^{2+}$ - and cAMPdependent signaling coordinately mediates biliary secretion and growth, ${ }^{14,39,42,44,49,50}$ we propose that blockage of $\mathrm{Ca}^{2+}$ (by the H1HR antagonist) and cAMP (by the H2HR antagonist) signaling may reciprocally inhibit cAMP and $\mathrm{Ca}^{2+}$ signaling, respectively. This explanation is also supported by the fact that the inhibitory effects of terfenadine and cimetidine (when administered together) on NRIC proliferation were not additive.

We have also shown that (1) histamine stimulation of NRIC proliferation is dependent on the activation of both the $\mathrm{IP}_{3} / \mathrm{Ca}^{2+}$ and the cAMP signaling pathways (blockage by both $\mathrm{Ca}^{2+}$ chelators and specific PKC and PKA inhibitors); (2) H1HR stimulation of small cholangiocyte growth a

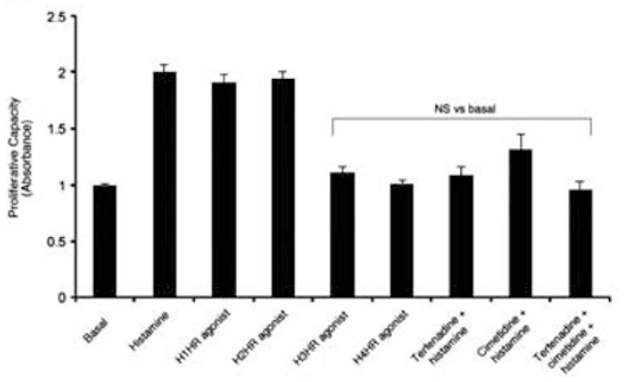

b

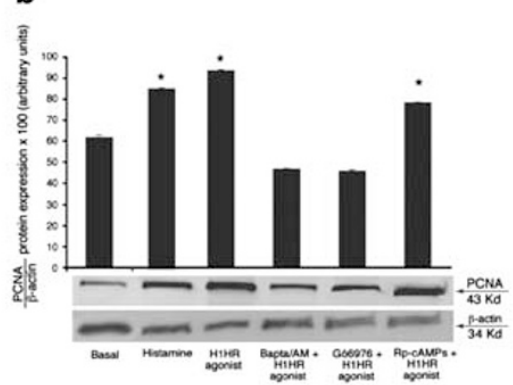

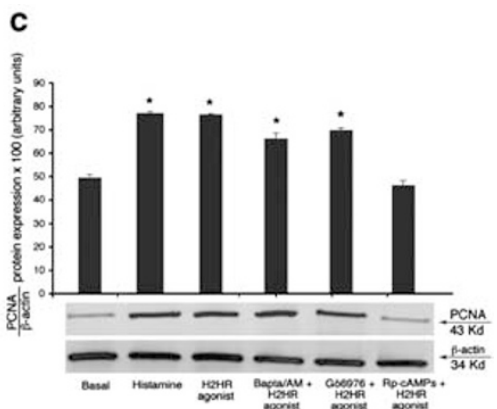

Figure 5 (a) Histamine, H1HR and H2HR (but not H3HR or H4HR) agonists increased NRIC proliferation. Histamine stimulation of NRIC proliferation was partly blocked by terfenadine and cimetidine. ${ }^{\star} P<0.05$ vs proliferation of NRIC treated in vitro with $0.2 \%$ BSA (basal). Data are mean \pm s.e.m. of seven experiments. $\mathrm{H} 1 \mathrm{HR}$ agonist $=\mathrm{HTMT}$ dimaleate; $\mathrm{H} 2 \mathrm{HR}$ agonist = amthamine dihydrobromide; $\mathrm{H} 3 \mathrm{HR}$ agonist $=\mathrm{RAMH}$; $\mathrm{H} 4 \mathrm{HR}=\mathrm{clobenpropit}$. (b and $\mathbf{c}) \mathrm{By}$ PCNA immunoblots, we demonstrated that: (b and c) H1HR and H2HR agonists (in addition to histamine) stimulate NRIC proliferation;

(b) H1HR-induced NRIC proliferation is blocked by BAPTA/AM and Gö6976 but not Rp-cAMPs; and (c) H2HR-induced NRIC proliferation is blocked by Rp-cAMPs but not BAPTA/AM and Gö6976. ${ }^{\star P}<0.05$ vs proliferation of NRIC treated in vitro with $0.2 \%$ BSA (basal). Data are mean \pm s.e.m. of six experiments. $\mathrm{H} 1 \mathrm{HR}$ agonist = HTMT dimaleate; $\mathrm{H} 2 \mathrm{HR}$ agonist = amthamine dihydrobromide. 

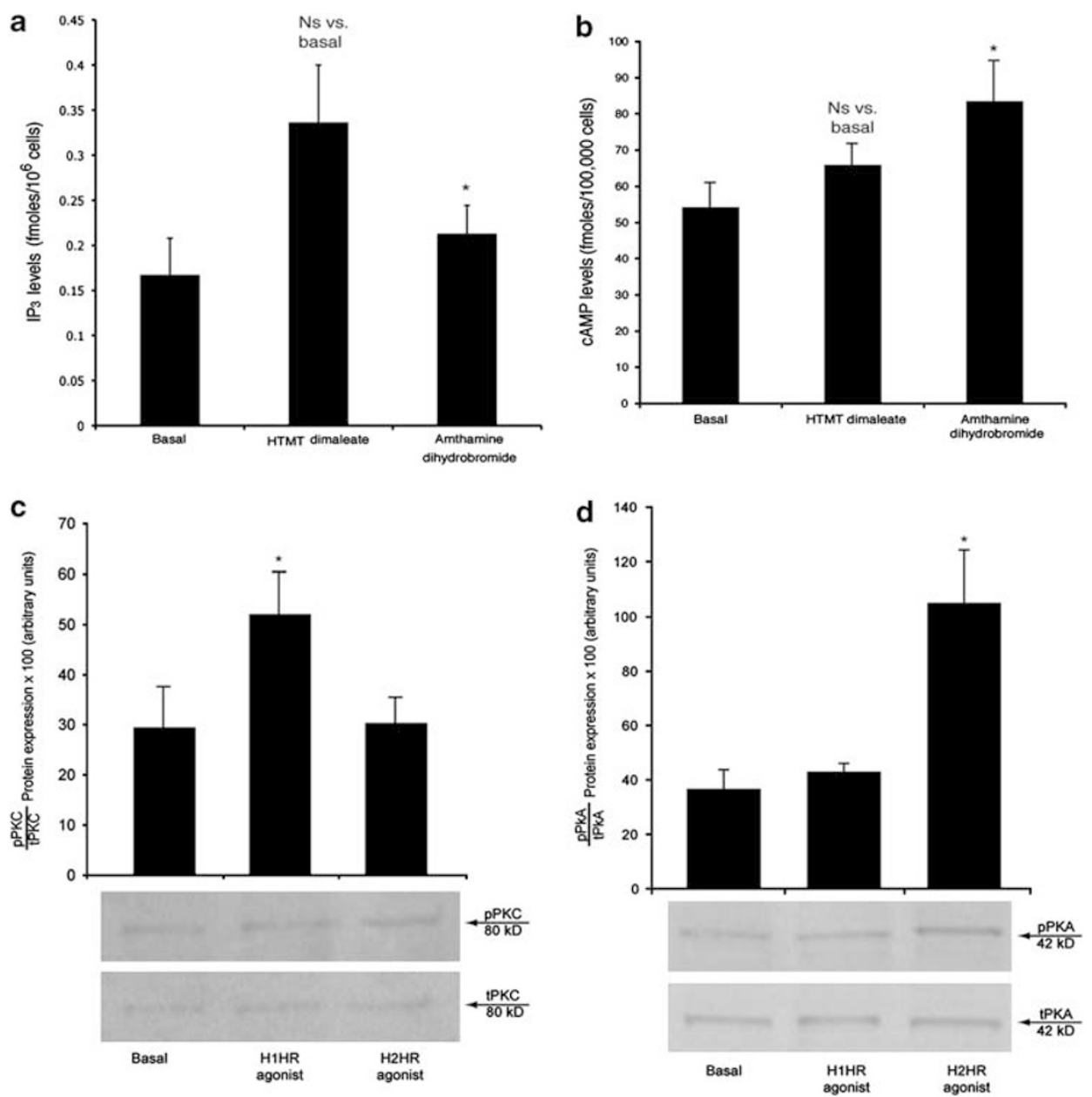

Figure 6 Effect of H1HR and H2HR agonists on (a) IP levels and (b) CAMP levels, (c) PKC phosphorylation and (d) PKA phosphorylation in NRIC. We demonstrated that HTMT dimaleate (a H1HR agonist) increases $\mathrm{IP}_{3}$ levels (a) and PKC (panel c) phosphorylation, whereas amthamine dihydrobromide (a H2HR agonist) enhances CAMP levels (b) and PKA phosphorylation (d). ${ }^{*} P<0.05$ vs proliferation of NRIC treated in vitro with $0.2 \%$ BSA (basal).

Data are mean \pm s.e.m. of six experiments.

depends on the activation of $\mathrm{IP}_{3} / \mathrm{Ca}^{2+} / \mathrm{PKC} \alpha$ signaling (proliferation blocked by $\mathrm{Ca}^{2+}$ chelators and PKC but not by PKA inhibitors); and (3) H2HR stimulation of large NRIC proliferation is mediated by cAMP-dependent PKA signaling (blockage by only PKA inhibitors). Further confirmation of differential signaling was found with evaluation of intracellular cAMP and $\mathrm{IP}_{3}$ levels, as well as PKC $\alpha$ and PKA phosphorylation. H1HR stimulation activates $\mathrm{IP}_{3}$ levels and PKC $\alpha$ phosphorylation, whereas $\mathrm{H} 2 \mathrm{HR}$ increases cAMP levels and PKA phosphorylation. The importance of signaling through differential pathways is important because in cholangiopathies, there is proliferation/damage of only specific bile ducts of different sizes. ${ }^{8,10,11,13,15,34}$ Cholangiopathies target both small and large cholangiocytes, ${ }^{8,10,11,34}$ and, thus, it may be important for histamine to have the ability to modulate cholangiocyte proliferation and/or loss through the activation of $\mathrm{HRs}$ that will induce stimulatory $(\mathrm{H} 1$ and $\mathrm{H} 2 \mathrm{H})$ and inhibitory (H3 and H4HR) effects on biliary growth.
After finding that $\mathrm{H} 1 \mathrm{HR}$ activates $\mathrm{Ca}^{2+}$-dependent $\mathrm{PKC} \alpha$ and knowing that $\mathrm{PKC} \alpha$ has a critical role in cholangiocyte function, ${ }^{14,39,41,42,50}$ we knocked down PKC $\alpha$ expression and evaluated the effect of HTMT dimaleate on NRIC proliferation. As no commercially kits are available for silencing PKA, we could not evaluate the role of PKA silencing on H2HRinduced large NRIC proliferation. Similar to what we have previously shown ${ }^{45}$ in cholangiocarcinoma cells using the $\mathrm{H} 3$ agonist, RAMH, we found here that the reduction of PKC $\alpha$ in NRICs ablates the stimulatory effects of HTMT dimaleate. PKC $\alpha$ has a critical role in the function of numerous cells and the loss of PKC $\alpha$ signaling can have a negative or positive impact on the proliferation of a number of epithelial including cholangiocytes. ${ }^{14,39-41,45,50}$ For example, PKC $\alpha$ has a stimulatory role in wound healing of human corneal epithelial cells after hepatocyte growth factor stimulation. ${ }^{51}$ In cancer, $\mathrm{PKC} \alpha$ has a stimulatory role enhancing the growth of certain cancers, ${ }^{52}$ whereas the activation of $\mathrm{PKC} \alpha$ 

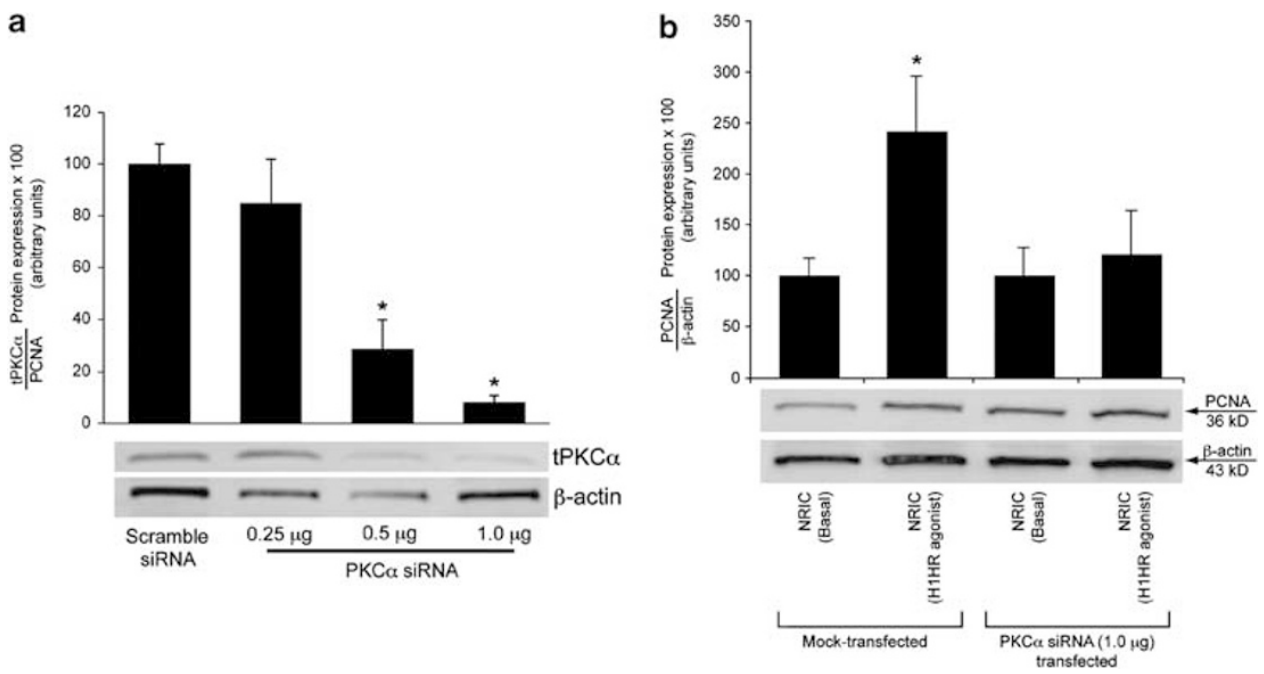

Figure 7 (a, b) Effect of (a) PKC $\alpha$ silencing on the (b) proliferation (by PCNA immunoblots) of NRIC after treatment with $0.2 \%$ BSA (basal) or HTMT dimaleate. In scrambled-transfected NRIC, HTMT dimaleate increased NRIC proliferation. In PKC $\alpha$-siRNA ( $1.0 \mu$ g) transfected cells ( $90 \%$ silenced efficiency), HTMT dimaleate failed to increase NRIC proliferation. ${ }^{\star} P<0.05$ vs proliferation of NRIC treated in vitro with $0.2 \%$ BSA (basal). Data are mean \pm s.e.m. of four experiments. H1HR agonist $=$ HTMT dimaleate.

modulates the inhibition of cholangiocarcinoma growth. ${ }^{42,45}$ Further studies are necessary to understand why activation of PKC $\alpha$ in biliary cells induces either inhibition or activation of hyperplastic and neoplastic biliary growth and secretin-stimulated ductal secretion (a functional index of biliary hyperplasia). ${ }^{14,39,41-43,50}$ One potential explanation for the differential effects of $\mathrm{PKC} \alpha$ on biliary growth may depend on the type of receptor (eg, M3 acetylcholine, insulin, gastrin or $\alpha 1$-adrenergic) or transporter (eg, $\mathrm{Na}^{+}$-dependent apical bile acid transporter) that are upregulated or downregulated after vagotomy, the treatment with the selected gastrointestinal hormone or bile salt feeding. ${ }^{14,39,41-43,50}$ A possible shortcoming of our study is that $\mathrm{PKC} \alpha$ may be not the only factor as other $\mathrm{Ca}^{2+}$-dependent $(\beta \mathrm{I}, \beta \mathrm{II}$ and $\gamma)$ and $\mathrm{Ca}^{2+}$ independent $(\delta, \varepsilon, \theta, \eta$ and $\zeta)$ PKC isoforms may be involved in H1HR stimulation of biliary growth.

Taken together, these findings implicate histamine and HRs as key factors in the regulation of normal cholangiocyte proliferation and function. Although endogenous histamine may activate numerous signaling mediators and pathways, it may be more important that stimulation of specific HRs is able to induce specific effects in target cells (possibly in small and large subpopulations of cholangiocytes) using different signaling pathways. In clinical situations in which certain subpopulations of cells are affected, the usage of specific agonists may help in the development of therapeutic treatments. For example, in a cholestatic state in which inflamed cholangiocytes are overproliferating, the usage of the H3HR agonist RAMH might aid in patient therapy to help decrease cholangiocyte proliferation. On the other hand, in a case of damaged or cholangiocyte loss, treatment with either an H1HR or H2HR agonist may increase proliferation when warranted and necessary for recovery.
As histamine is released by mast cells, ${ }^{53}$ further studies are warranted to evaluate how mast cells may be contributing to cholangiocyte proliferation, a topic that is a topic of future work in our laboratory. In support of this novel topic, it has been demonstrated that during cholestasis, mast cell quantities increase. ${ }^{53}$ Increased mast cell quantity would likely lead to increased histamine release into the microenvironment, thus modulating biliary functions. Furthermore, ongoing studies from our laboratory aim to demonstrate that bile acids (that have a key role in the regulation of biliary functions and stimulate histamine secretion from mast cells $^{40,41,44,50,54}$ affect cholangiocyte growth by releasing histamine from proliferating mast cells.

\section{ACKNOWLEDGEMENTS}

This work was supported by the Dr Nicholas C Hightower Centennial Chair of Gastroenterology from Scott and White Hospital, a VA Research Career Scientist Award, a VA Merit award and NIH grants DK58411 and DK76898 to Dr Alpini, by a MIUR grant 2003060137_004 to the Department of Gastroenterology, a grant award from Health and Labour Sciences Research Grants for the Research on Measures for Intractable Diseases (from the Ministry of Health, Labour and Welfare of Japan) and from Grant-in-Aid for Scientific Research C (21590822) from JSPS to Dr Ueno, by University funds to Dr Onori and University Funds from University 'Sapienza' of Rome, MIUR grant 2009X84L84 and FIB grant \#RAP10Z7FS to Professor Gaudio and an NIH K01 grant award (DK078532) to Dr DeMorrow.

\section{DISCLOSURE/CONFLICT OF INTEREST}

The authors declare no conflict of interest.

1. Alpini G, Roberts S, Kuntz SM, et al. Morphological, molecular, and functional heterogeneity of cholangiocytes from normal rat liver. Gastroenterology 1996;110:1636-1643.

2. Glaser S, Gaudio E, Rao A, et al. Morphological and functional heterogeneity of the mouse intrahepatic biliary epithelium. Lab Invest 2009;89:456-469. 
3. Alpini G, Lenzi R, Sarkozi L, et al. Biliary physiology in rats with bile ductular cell hyperplasia. Evidence for a secretory function of proliferated bile ductules. J Clin Invest 1988;81:569-578.

4. Nathanson MH, Boyer JL. Mechanisms and regulation of bile secretion. Hepatology 1991;14:551-566.

5. Kato A, Gores GJ, LaRusso NF. Secretin stimulates exocytosis in isolated bile duct epithelial cells by a cyclic AMP-mediated mechanism. J Biol Chem 1992;267:15523-15529.

6. Alpini $G$, Ulrich $C$, Roberts $S$, et al. Molecular and functional heterogeneity of cholangiocytes from rat liver after bile duct ligation. Am J Physiol Gastrointest Liver Physiol 1997;272:G289-G297.

7. Banales JM, Arenas F, Rodriguez-Ortigosa CM, et al. Bicarbonate-rich choleresis induced by secretin in normal rat is taurocholate-dependent and involves AE2 anion exchanger. Hepatology 2006;43:266-275.

8. Alpini G, Glaser $S$, Ueno $Y$, et al. Heterogeneity of the proliferative capacity of rat cholangiocytes after bile duct ligation. Am J Physio Gastrointest Liver Physiol 1998;274:G767-G775.

9. LeSage $\mathrm{G}$, Glaser $\mathrm{S}$, Gubba $\mathrm{S}$, et al. Regrowth of the rat biliary tree after $70 \%$ partial hepatectomy is coupled to increased secretin-induced ductal secretion. Gastroenterology 1996;111:1633-1644.

10. Alpini G, Prall RT, LaRusso NF. The pathobiology of biliary epithelia. The Liver; Biology \& Pathobiology, 4 edn IM Arias, JL Boyer, FV Chisar et al (eds) 4 edn Philadelphia, PA: Lippincott Williams \& Wilkins, 2001; 421-435.

11. LeSage G, Glaser S, Marucci L, et al. Acute carbon tetrachloride feeding induces damage of large but not small cholangiocytes from BDL rat liver. Am J Physiol Gastrointest Liver Physiol 1999;276:G1289G1301.

12. Alpini G, Ulrich CD, Phillips JO, et al. Upregulation of secretin receptor gene expression in rat cholangiocytes after bile duct ligation. Am J Physiol Gastrointest Liver Physiol 1994;266:G922-G928.

13. Francis $\mathrm{H}$, Glaser $\mathrm{S}$, Ueno $\mathrm{Y}$, et al. cAMP stimulates the secretory and proliferative capacity of the rat intrahepatic biliary epithelium through changes in the PKA/Src/MEK/ERK1/2 pathway. J Hepatol 2004;41: 528-537.

14. Glaser $S$, Benedetti A, Marucci $L$, et al. Gastrin inhibits cholangiocyte growth in bile duct-ligated rats by interaction with cholecystokinin-B/ Gastrin receptors via D-myo-inositol 1,4,5-triphosphate-, $\mathrm{Ca}\left({ }^{2+}\right)$-, and protein kinase $\mathrm{C}$ alpha-dependent mechanisms. Hepatology 2000:32:17-25.

15. Francis $\mathrm{H}$, Glaser $\mathrm{S}$, DeMorrow $\mathrm{S}$, et al. Small mouse cholangiocytes proliferate in response to $\mathrm{H} 1$ histamine receptor stimulation by activation of the $\mathrm{IP}_{3} /$ CaMK I/CREB pathway. Am J Physiol Cell Physiol 2008;295:C499-C513.

16. Francis $H$, Franchitto $A$, Ueno $Y$, et al. $H 3$ histamine receptor agonist inhibits biliary growth of $\mathrm{BDL}$ rats by downregulation of the CAMP-dependent PKA/ERK1/2/ELK-1 pathway. Lab Invest 2007;87: 473-487.

17. Rosenthaler J, Guirard BM, Chang GW, et al. Purification and properties of histidine decarboxylase from Lactobacillus 30a. Proc Natl Acad Sci USA 1965;54:152-158.

18. Repka-Ramirez MS. New concepts of histamine receptors and actions. Curr Allergy Asthma Rep 2003;3:227-231.

19. Nguyen T, Shapiro DA, George SR, et al. Discovery of a novel member of the histamine receptor family. Mol Pharmacol 2001;59:427-433.

20. Molina-Hernandez A, Velasco I. Histamine induces neural stem cell proliferation and neuronal differentiation by activation of distinct histamine receptors. J Neurochem 2008;106:706-717.

21. Medina VA, Rivera ES. Histamine receptors and cancer pharmacology. Br J Pharmacol 2010;161:755-767.

22. Dickenson JM. Stimulation of protein kinase B and p70 S6 kinase by the histamine $\mathrm{H} 1$ receptor in DDT1MF-2 smooth muscle cells. $\mathrm{Br} J$ Pharmacol 2002;135:1967-1976.

23. Mitsuhashi M, Mitsuhashi T, Payan D. Multiple signaling pathways of histamine $\mathrm{H} 2$ receptors (Identification of an $\mathrm{H} 2$ receptor-dependent $\mathrm{Ca}^{2+}$ mobilization pathway in human $\mathrm{HL}-60$ promyelocytic leukemia cells). J Biol Chem 1989;264:18356-18362.

24. Schultheiss G, Hennig B, Schunack W, et al. Histamine-induced ion secretion across rat distal colon: involvement of histamine $\mathrm{H} 1$ and $\mathrm{H} 2$ receptors. Eur J Pharmacol 2006;546:161-170.

25. Karavodin L, Jensen R, Sarno M, et al. Toxicology and toxicokinetics of acute and subchronic administration of histamine dihydrochloride in rats. Drug Chem Toxicol 2003;26:35-49.
26. Farzin D, Asghari L, Nowrouzi M. Rodent antinociception following acute treatment with different histamine receptor agonists and antagonists. Pharmacol Biochem Behav 2002;72:751-760.

27. Coruzzi G, Gambarelli E, Bertaccini G, et al. Cardiovascular effects of the novel histamine $\mathrm{H} 2$ receptor agonist amthamine: interaction with the adrenergic system. Naunyn Schmiedebergs Arch Pharmacol 1996;353:417-422.

28. Gantner F, Sakai K, Tusche MW, et al. Histamine $h(4)$ and $h(2)$ receptors control histamine-induced interleukin-16 release from human CD8(+) T cells. J Pharmacol Exp Ther 2002;303:300-307.

29. Ishii M, Vroman B, LaRusso NF. Isolation and morphologic characterization of bile duct epithelial cells from normal rat liver. Gastroenterology 1989;97:1236-1247.

30. Rutenburg AM, Kim H, Fischbein JW, et al. Histochemical and ultrastructural demonstration of $\gamma$-glutamyl transpeptidase activity. J Histochem Cytochem 1969;17:517-526.

31. Alpini G, Phinizy JL, Glaser S, et al. Development and characterization of secretin-stimulated secretion of cultured rat cholangiocytes. Am J Physiol Gastrointest Liver Physiol 2003;284:G1066-G1073.

32. Wadugu $\mathrm{BA}, \mathrm{Ng} \mathrm{C}$, Bartley $\mathrm{BL}$, et al. DNA interstrand cross-linking activity of (1-Chloroethenyl)oxirane, a metabolite of beta-chloroprene. Chem Res Toxicol 2010;23:235-239.

33. Mancinelli R, Onori P, Gaudio E, et al. Follicle-stimulating hormone increases cholangiocyte proliferation by an autocrine mechanism via CAMP-dependent phosphorylation of ERK1/2 and Elk-1. Am J Physiol Gastrointest Liver Physiol 2009;297:G11-G26.

34. Mancinelli R, Franchitto A, Gaudio E, et al. After damage of large bile ducts by gamma-aminobutyric acid, small ducts replenish the biliary tree by amplification of calcium-dependent signaling and de novo acquisition of large cholangiocyte phenotypes. Am J Pathol 2010;176:1790-1800.

35. Mancinelli R, Onori P, Gaudio E, et al. Taurocholate feeding to bile duct ligated rats prevents caffeic acid-induced bile duct damage by changes in cholangiocyte VEGF expression. Exp Biol Med (Maywood) 2009;234:462-474.

36. Ghosh AK, Hirasawa N, Ohuchi K. Enhancement by histamine of vascular endothelial growth factor production in granulation tissue via $\mathrm{H}(2)$ receptors. Br J Pharmacol 2001;134:1419-1428.

37. Medina V, Croci M, Crescenti $E$, et al. The role of histamine in human mammary carcinogenesis: $\mathrm{H} 3$ and $\mathrm{H} 4$ receptors as potential therapeutic targets for breast cancer treatment. Cancer Biol Ther 2008;7:28-35.

38. Gaudio E, Barbaro B, Alvaro D, et al. Vascular endothelial growth factor stimulates rat cholangiocyte proliferation via an autocrine mechanism. Gastroenterology 2006;130:1270-1282.

39. LeSage $G$, Marucci $L$, Alvaro $D$, et al. Insulin inhibits secretin-induced ductal secretion by activation of PKC alpha and inhibition of PKA activity. Hepatology 2002;36:641-651.

40. Alpini G, Kanno N, Phinizy JL, et al. Tauroursodeoxycholate inhibits human cholangiocarcinoma growth via $\mathrm{Ca}^{2+}{ }_{-}$, PKC-, and MAPKdependent pathways. Am J Physiol Gastrointest Liver Physiol 2004;286:G973-G982.

41. Alpini G, Ueno Y, Glaser S, et al. Bile acid feeding increased proliferative activity and apical bile acid transporter expression in both small and large rat cholangiocytes. Hepatology 2001;34:868-876.

42. Kanno N, Glaser S, Chowdhury $\mathrm{U}$, et al. Gastrin inhibits cholangiocarcinoma growth through increased apoptosis by activation of $\mathrm{Ca}^{2+}$-dependent protein kinase C-alpha. J Hepatol 2001;34:284-291.

43. LeSage G, Alvaro D, Glaser $S$, et al. Alpha-1 adrenergic receptor agonists modulate ductal secretion of $\mathrm{BDL}$ rats via $\mathrm{Ca}\left({ }^{2+}\right)$ - and PKCdependent stimulation of CAMP. Hepatology 2004;40:1116-1127.

44. Marzioni $M$, Francis $\mathrm{H}$, Benedetti $\mathrm{A}$, et al. $\mathrm{Ca}^{2+}$-dependent cytoprotective effects of ursodeoxycholic and tauroursodeoxycholic acid on the biliary epithelium in a rat model of cholestasis and loss of bile ducts. Am J Pathol 2006;168:398-409.

45. Francis $\mathrm{H}$, Onori $\mathrm{P}$, Gaudio $\mathrm{E}$, et al. $\mathrm{H} 3$ histamine receptor-mediated activation of protein kinase Calpha inhibits the growth of cholangiocarcinoma in vitro and in vivo. Mol Cancer Res 2009:7:1704-1713.

46. Mine T, Kojima I, Ogata E. Mechanism of glycogenolytic action of histamine in rat hepatocytes. Am J Physiol Gastrointest Liver Physiol 1991;261:G1000-G1004. 
47. Garcia-Sainz JA, Macias-Silva M, Olivares-Reyes A, et al. Histamine activates phosphorylase and inositol phosphate production in guinea pig hepatocytes. Eur J Pharmacol 1992;227:325-331.

48. Alpini G, Franchitto A, DeMorrow S, et al. Activation of alpha(1) adrenergic receptors stimulate the growth of small mouse cholangiocytes via calcium-dependent activation of nuclear factor of activated T cells 2 and specificity protein 1. Hepatology 2011;53: 628-639.

49. Strazzabosco M, Fiorotto R, Melero S, et al. Differentially expressed adenylyl cyclase isoforms mediate secretory functions in cholangiocyte subpopulation. Hepatology 2009;50:244-252.

50. Alpini G, Baiocchi L, Glaser S, et al. Ursodeoxycholate and tauroursodeoxycholate inhibit cholangiocyte growth and secretion of $\mathrm{BDL}$ rats through activation of PKC alpha. Hepatology 2002;35: 1041-1052.

51. Sharma GD, Ottino $P$, Bazan NG, et al. Epidermal and hepatocyte growth factors, but not keratinocyte growth factor, modulate protein kinase Calpha translocation to the plasma membrane through 15(S)hydroxyeicosatetraenoic acid synthesis. J Biol Chem 2005;280:7917-7924.

52. Aziz MH, Manoharan HT, Sand JM, et al. Protein kinase Cepsilon interacts with Stat3 and regulates its activation that is essential for the development of skin cancer. Mol Carcinog 2007;46:646-653.

53. Francis $\mathrm{H}$, Meininger $\mathrm{CJ}$. A review of mast cells and liver disease: what have we learned? Dig Liver Dis 2010;42:529-536.

54. Quist RG, Ton-Nu HT, Lillienau J, et al. Activation of mast cells by bile acids. Gastroenterology 1991;101:446-456. 